\section{Hypothesized Epitope Localization in Hypersensitivity Reactions to Iodinated Contrast Media}

Borras $\mathrm{J}^{1}$, El-Qutob D 2 , Lopez $\mathrm{R}^{3}$, Enrique $\mathrm{E}^{4}$

${ }^{1}$ Unit of Allergy, Consorcio Hospitalario Provincial, Castellon, Spain

${ }^{2}$ Unit of Allergy, Hospital Universitario de la Plana in Vila-Real, Spain

${ }^{3}$ Section of Allergy, Hospital General Universitari de Castelló, Castellon, Spain

${ }^{4}$ Medical Research Institute Hospital La Fe, Valencia, Spain

J Investig Allergol Clin Immunol 2019; Vol. 29(1): 82-83 doi: 10.18176/jiaci.0341

Key words: lodinated contrast media. Drug allergy. Epitope. Crossreactivity.

Palabras clave: Contrastes yodados. Alergia a fármacos. Epítopo. Reactividad cruzada.

Iodinated contrast media (ICM) generally have a good safety profile. Adverse effects from the intravascular administration of ICM, while not rare, are generally mild and self-limiting. However, life-threatening reactions and deaths can occur. Although the underlying mechanisms of these reactions have traditionally been considered nonallergic and due to nonspecific mast cell and basophil activation, positive skin test and basophil activation test (BAT) results suggested a specific allergic mechanism in some situations [1]. In fact, the grade of severity of the reaction is significantly higher among patients with positive skin test results [2].

All currently used ICM are chemical modifications of a 2,4,6-tri-iodinated benzene ring. They are classified on the basis of their physical and chemical characteristics, including their chemical structure, osmolality, iodine content, and ionization in solution. Nonionic monomers are the contrast agents of choice. In addition to their nonionic nature and lower osmolality, they are potentially less chemotoxic than ionic monomers. There are 3 types of low-osmolality ICM: nonionic monomers, ionic dimers, and nonionic dimers.

Skin testing appears to be a useful tool for the evaluation and diagnosis of immediate hypersensitivity reactions to ICM and may play an important role in the selection of a safe product for future administration in previous reactors [3]. Some authors have proposed controlled challenge testing based on skin test results to identify alternative and safe non-cross-reactive ICM for future diagnostic and therapeutic procedures [4]. Other authors found skin testing (intradermal tests [IDTs] and patch tests) to be useful in implicating an ICM as the cause of a delayed hypersensitivity reaction. These authors challenged ICM-allergic patients using iobitridol and recorded negative skin test results, because the chemical structure of this agent differs somewhat from that of the culprit ICM [5]. The BAT is used to detect basophil activation markers (CD45, CD18, and CD63) by means of flow cytometry. Some studies report positive BAT results in $62.5 \%$ of patients with hypersensitivity to ICM confirmed by positive skin and/or provocation tests [6].

We present 2 cases of ICM allergy in which an alternative contrast was found.

The first patient was a 77-year-old man who presented general discomfort, severe dizziness, shortness of breath, bilateral palpebral angioedema, generalized erythema, and hypotension immediately after intravenous administration of $150 \mathrm{cc}$ of iodixanol 3 days before he underwent a computed tomography scan with $50 \mathrm{cc}$ of iohexol, which he tolerated well.

After signing an informed consent document, the patient underwent skin tests (prick and IDT) with iodixanol, iohexol, iobitridol, and ioversol. Only iodixanol was positive in the IDT at a 1:1000 dilution. The BAT was positive for iodixanol (concentration [C] 2, 13.56\%; stimulation index [SI] 2, 4.14) and iopamidol (concentration 1, 3.69\%; SI1, 4.46), and negative for iobitridol. In view of these results, a challenge test was carried out in the intensive care unit with intravenous administration of $100 \mathrm{cc}$ of iobitridol $(1,5,15,30$, and $49 \mathrm{cc}$ with an interval of 25 minutes between them), with good tolerance after 90 minutes of observation. The second patient was a 52-year-old woman who, in May 2016, experienced an anaphylactoid reaction immediately after intravenous administration of iopromide for a computed tomography scan. The reaction manifested as dizziness, nausea, loss of consciousness with urinary incontinence, generalized erythema, and hypotension. BAT was positive for iomeprol (C1, 5.44\% [SI1, 1.38]; C2, 9.05\% [SI2, 2.83]) and iopamidol (C1, 6.18\% [SI1, 2.11]; C2, 9.46\% [SI2, 2.94]). The patient was diagnosed with anaphylactic reaction to iopromide and was prohibited from receiving ICM. Eighteen months later, the patient was referred to select an alternative ICM. After signing the informed consent document, skin tests were performed with iopromide, iomeprol, iodixanol, iohexol, iobitridol, and ioversol, all of which yielded negative results. BAT was positive for iopromide (C1, 3.24\% [SI1, 0.82]; C2, 5.76\% [SI2, 1.46]) and iomeprol (C1, 5.44\% [SI1, 1.38]; C2, 9.05\% [SI2, 2.83]), and negative for iobitridol. The cut-off point to assess the positivity of the BAT and determine the SI were as follows: cut-off concentration $\geq 5 \%$, SI $\geq 2$, and concentrations of ICM used for the BAT of $100 \mu \mathrm{g} / \mathrm{mL}$ and $1000 \mu \mathrm{g} / \mathrm{mL}$, following the dilutions and reference values used in previous publications [7].

In view of these results, a challenge test was carried out with up to $100 \mathrm{cc}$ of iobitridol, which both patients tolerated well. The patients were diagnosed with allergy to iodixanol and iopromide, respectively, and were advised not to receive ICM, except iobitridol, which both tolerated.

Cross-reactivity between ICM is less common in immediate reactions and is related to chemical structure [8]. Some of the patients who experience severe immediate reactions also react to other ICM to which they had not been previously exposed, probably because the core chemical structure common to ICM is part of the antigenic determinant and thus induces crossreactivity [9]. In some studies, cross-reactivity was found in $20 \%$ of patients with positive skin test results [2]. Some authors have hypothesized that cross-reactivity between different ICM is a result of the presence of ICM-specific T cells, some of 


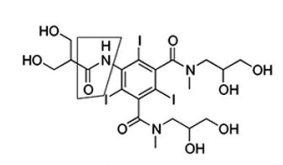

lobitridol

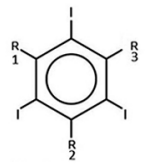

Nonionic monomer

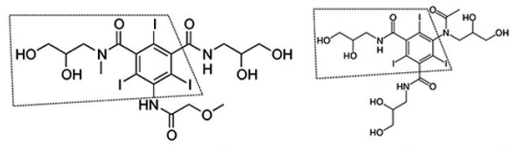

lopromide

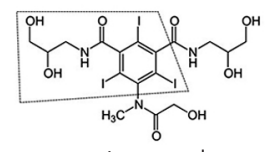

lomeprol

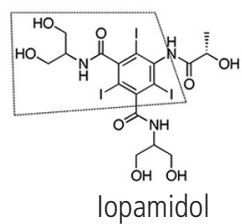

Figure. Chemical structure of iodinated contrast media and possible location of the epitope responsible for cross-reactivity.

which show a broad cross-reactivity pattern. Lerch et al [10] reported that among nonionic ICM, iobitridol showed low T-cell reactivity in 2 patients who were allergic to iohexol and iomeprol, respectively, with delayed reactions [10].

In the cases we report, we observed good tolerance to iobitridol as an alternative ICM. This was due in large part to its different chemical structure (Figure). The side chain R1 in iobitridol differs from that of other ICM. In contrast, the side chain R2 is very similar in all ICM. It could be hypothesized that this region is an epitope and, therefore, the culprit of the cross-reactivity between the remaining ICM. Evidently, more studies would be necessary to confirm this hypothesis.

We present 2 cases of allergy to ICM in which BAT enabled us to choose a safe alternative contrast agent for the challenge test.

\section{Funding}

The authors declare that no funding was received for the present study.

\section{Conflicts of Interest}

The authors declare that they have no conflicts of interest. challenge testing. J Investig Allergol Clin Immunol. 2013;23(3):183-9.

5. Hasdenteufel F, Waton J, Cordebar V, Studer M, Collignon O, Luyasu $\mathrm{S}$, et al. Delayed hypersensitivity reactions caused by iodixanol: an assessment of cross-reactivity in 22 patients. J Allergy Clin Immunol. 2011 Dec;128(6):1356-7.

6. Salas M, Gomez F, Fernandez TD, Dona I, Aranda A, Ariza A, et al. Diagnosis of immediate hypersensitivity reactions to radiocontrast media. Allergy. 2013 Sep;68(9):1203-6.

7. Pinnobphun P, Buranapraditkun S, Kampitak T, Hirankarn N, Klaewsongkram J. The diagnostic value of basophil activation test in patients with an immediate hypersensitivity reaction to radiocontrast media. Ann Allergy Asthma Immunol. 2011 May; 106(5):387-93.

8. Yoon SH, Lee SY, Kang HR, Kim JY, Hahn S, Park CM, et al. Skin tests in patients with hypersensitivity reaction to iodinated contrast media: a meta-analysis. Allergy. 2015 Jun;70(6):62537.

9. Rosado Ingelmo A, Dona Diaz I, Cabanas Moreno R, Moya Quesada MC, Garcia-Aviles C, Garcia Nunez I, et al. Clinical Practice Guidelines for Diagnosis and Management of Hypersensitivity Reactions to Contrast Media. J Investig Allergol Clin Immunol. 2016;26(3):144-55

10. Lerch $M$, Keller $M$, Britschgi $M$, Kanny $G$, Tache $V$, Schmid $D A$, et al. Cross-reactivity patterns of $T$ cells specific for iodinated contrast media. J Allergy Clin Immunol. 2007 Jun;119(6):1529-36.

Manuscript received June 25, 2018; accepted for publication October 26, 2018.

David El-Qutob

Unit of Allergy Hospital Universitario de la Plana, Vila-Real Carretera Vila-Real-Burriana Km. 0.5 Vila-Real 12540 Castellón, Spain E-mail: elqutob@comv.es

\section{References}

1. Trcka J, Schmidt C, Seitz CS, Bröcker E-B, Gross GE, Trautmann A. Anaphylaxis to lodinated Contrast Material: Nonallergic Hypersensitivity or IgE-Mediated Allergy? AJR Am J Roentgenol. 2008;190(3):666-70.

2. Morales-Cabeza C, Roa-Medellin D, Torrado I, De Barrio M, Fernandez-Alvarez C, Montes-Acenero JF, et al. Immediate reactions to iodinated contrast media. Ann Allergy Asthma Immunol. 2017 Dec;119(6):553-7.

3. Brockow K, Christiansen C, Kanny G, Clement O, Barbaud A, Bircher $A$, et al. Management of hypersensitivity reactions to iodinated contrast media. Allergy. 2005 Feb;60(2):150-8.

4. Prieto-Garcia A, Tomas M, Pineda R, Tornero P, Herrero T, Fuentes $V$, et al. Skin test-positive immediate hypersensitivity reaction to iodinated contrast media: the role of controlled 